\title{
Effectiveness of Guided Writing in Teaching Composition
}

\section{- Dipendra Kumar Khatri}

\begin{abstract}
This article summarizes the study conducted to find out the effectiveness of guided writing in teaching composition. Fifty-two students of grade nine studying at Khelnechour Secondary School, Surkhet were the sample population of this research. The researcher requested one of the teachers to involve in the practical teaching for carrying out the research. The tests (pre-test and post test) were the major tools for data collection. The students were ranked from the first to the fifty-second position based on the results of the pre-test. They were divided into two groups based on odd-even ranking of the individual scores. Then, experimental group was taught through guided writing activities whereas controlled group was taught without guided writing activities. Each groups attended thirty lessons. Then the post-test was administered. The results of these two tests (Pre and Post) were compared and found that guided writing activities were more effective in teaching composition.
\end{abstract}

Key words: Effectiveness, guided writing, composition

\section{Introduction}

Writing is one of the most important skills for learning a new language, which needs proper handling of the mechanics of writing to make sensible sentences and paragraphs.

We can argue with Odell, (1981, p. 43) as cited in Khaniya (2005, p. 137) where writing is explained as a good activity to improve our understanding of any subject.' The assumption is that the knowledge or ideas in a crude form may be refined by trying to put them on the paper. The argument is that writing is an activity which involves the writer in the process of formulating ideas, then testing and confirming them.

Writing is such a skill which keeps us active as we communicate with one another and transmit our culture, ideas and thoughts from one generation to another, it provides us chances to acquire others' ideas, feelings and thoughts in 'a good way. Altogether there are four skills of language learning: listening, speaking, reading and writing. The writing skill is the output of listening, speaking and reading. Besides, writing is the second manifestation of language, speech being the primary one. 
Rivers says (1968, p. 242) "Writing can be the act of putting down in conventional graphic form something which has been spoken". So it can be said that written language is message oriented which convey message accurately, effectively and appropriately.

\section{Guided Writing}

The stage of guided writing is more developed than that of copying, reproduction and recombination. In this stage, the learners are given some freedom in the selection of lexical items and structural patterns, but they have to follow the given suggestions regarding the content.

Raines (1983, p. 103) explains the concept of guided composition as "... it gives students some but not all of the content and form of the sentences they will use. Their finished products will thus be similar but not exactly alike. Students are given a first sentence, a last sentence, an outline to fill out, a series of questions to respond to, or information to include in their piece of writing."

Thus, guided writing is supplied with information in the form of some clues or points. Students are asked to select the information from the input. Then, students use all information correctly in short paragraphs. They write or describe something according to the guidelines. It may be a notice, note, telegram, dialogue, etc.

At the guided writing stage, the learner is given different exercises; completion exercises, replacement exercises, expansion of a simple sentence, writing summaries of stories and rewriting a story in dialogue form or a dialogue in narrative form etc. In the completion exercises, parts of sentences are given and each learner will be expected to construct an individual answer by his/her choice of completion. With replacement exercises each learner is given the opportunity to express new means by replacing a section of the sentence with a number of different phrases. Similarly, the learner can expand a simple sentence by addition of modifying words or phrases, or the inclusion of further information. The skeleton of a story or dialogue or an outline given for a description or narration based on pictures or succession of pictures may be supplied for the development by the students. This stage restricts the semantic area within which the students may express him/herself but leaves him/her free to vary such elements as person, tense, number.

Thus, guided writing exercises can be handled by giving 'skeleton' where students are expected to develop as a full text. Similarly a picture can be presented expecting to describe. Likewise a set of instructions, questions can be given where following instructions, answering questions a full text is formed. If the beginning and end of a story is given expecting to develop a full story that is also guided writing.

\section{Composition}

Writing composition is the final stage on the development of the writing skill. In this stage, students are free to make their own choice of words and organization to express their ideas. It is also known as creative writing. Writing composition requires a careful planning and a stage-wise procedures. Composition presupposes mastery of the structures and vocabularies required for writing the composition and is primary concerned with the logical arrangement of one's thoughts and ideas on the subject.

Pincas (1993, p. 110) defines "free writing is seen as the aim of a specific set of writing 


\section{Effectiveness of Guided Writing in Teaching Composition}

exercises:' the ability to write freely what has been taught', not 'the ability to write anything at all'."

So, free writing is an extended composition which is not guided or controlled. Students are asked exercises as writing paragraphs, essays, notices, reports, letters, diaries etc on the given topics where they are required to express their own opinions with careful planning. The other types of exercises are narration (an incident, story), description (form of paragraph or essay), explanation (the reasons for something), replying (in the form of a letter or application), summarization etc.

In this stage only title or topic is provided, and students do everything else. Students are free to make use of any structure and vocabulary items that $\mathrm{s} /$ he likes. Free composition is open-ended, in which each student is free to express his/her ideas in his/her own language. A free composition is one in which there are no restrictions on pupils for use of vocabulary and structure, there are usually no restriction on the length of composition, pupils are free to develop the ideas about the topic, and pupils are free to think and supply their ideas.

\section{Objectives of the study}

The objectives of this study were:

(a) To find out the effectiveness of the guided writing in teaching composition.

(b) To compare the effectiveness of guided writing in terms of following variables:

- Item-based; describing activities vs person vs place vs narrating event vs narrating story

\section{Methodology}

The methodology adopted during the study was as follows:

\section{Primary sources of data}

The primary sources of data collection for this research were grade nine students of Khelnechour Secondary School, Surkhet.

\section{Secondary sources of data}

The secondary sources for this research were related books, e.g. Khaniya (2005), Rivers (1968), Pincas (1993), Journals, articles, and many other types of researches.

\section{Sample population}

The sample population of this study were fiftytwo students of grade nine from Khelnechour Secondary School, Surkhet.

\section{Sampling procedure}

The researcher selected Shree Khelnechour Secondary School of Surkhet by using non-random, judgemental sampling procedure. 'Fifty-two' students of grade nine were taken for the study purposively. Those students were divided into two groups; experimental and controlled groups using systematic random sampling. The researcher tried to maintain equal proficiency level of both the groups with the help of ranking procedure (odd and even) from $1^{\text {st }}$ to last position on the basis of merit list prepared after the result of the pre-test.

\section{Tools for data collection}

The main tool for data collection was the test designed for the purpose of collecting the data. The test items were designed to assess the writing (free composition) ability of the students. The 
same test items were used in both pre-test and post-test.

\section{Process of data collection}

The researcher used the following procedures to collect the data from the primary sources.

a. At first, the researcher visited the selected school and talked to the authority and got permission to carry out the study. The researcher explained the purpose and the process of the research and assured the subjects of the confidentiality.

b. The researcher selected the students of Grade Nine according to the availability and feasibility of the study.

c. The researcher developed the test items for the pre-test and post-test and the lesson plans for teaching.

d. A pre-test was administered to identify the level of proficiency in writing composition prior to the experiment.

e. The students/subjects were divided into two groups in such a way that both the groups were supposed to be equal in terms of their writing ability.

f. The students were ranked from $1^{\text {st }}$ to last position on the basis of the merit list prepared after the result of the pre-test.

g. The researcher taught both the groups side by side, 30 lessons separately. Group 'A' was taught writing composition using guided writing activities and the group B was taught using non-guided activities (i.e. through explanation, oral instructions and dictations).

h. The teaching was conducted for a month, two periods in a day of $2 \mathrm{hrs}$
(1 hour to group A and 1 hour to group B).

i. At last, the post test was administered using the same set of questions which were used in the pre-test to both the experimental (A) and controlled (B) groups. The result of both pre-test and post-test were recorded as the individual raw scores, tabulated on the basis of merit list, compared group wise in the pre-test and post-test and analyzed on the basis of the average increment percentage of both the groups from pretest to the post-test to determine the effectiveness of the guided writing in teaching composition.

\section{Data analysis}

The data are tabulated in the following main headings:

- Holistic comparison

- Test-based comparison

- Item based comparison of pre-test and post-test between the two groups (experimental and controlled)

\section{Holistic comparison}

The average increment percentage of the experimental group and the controlled group:

Table 1: Holistic Comparison

\begin{tabular}{|c|c|c|c|}
\hline \multirow[b]{2}{*}{ Categories } & \multicolumn{2}{|c|}{ Total Increment } & \multirow{2}{*}{$\begin{array}{l}\text { Difference } \\
\text { between } \\
\text { Exp. and } \\
\text { Con. groups }\end{array}$} \\
\hline & $\begin{array}{c}\text { Exp. } \\
\text { group } \\
\text { In \% }\end{array}$ & $\begin{array}{l}\text { Con. } \\
\text { group } \\
\text { In \% }\end{array}$ & \\
\hline Descriptive writing & 38.44 & 27.38 & 11.06 \\
\hline Narrative writing & 25.67 & 13.85 & 11.82 \\
\hline Total & 64.11 & 41.23 & 22.88 \\
\hline Average & 32.05 & 20.61 & 11.44 \\
\hline
\end{tabular}

The average increment score of experimental group was 32.05 percent from the point of 


\section{Effectiveness of Guided Writing in Teaching Composition}

pre-test whereas, the average increment score of controlled group was 20.61 percent. The experimental group had 11.44 percent more average increment than that of controlled group in total categories of the items denoted/inferred that there was significant difference between the two ways of teaching composition writing.

\section{Test-based comparison}

This comparison based on the scores in the two tests; pre-test and post-test:

Raw scores of experimental and controlled group in pre-test and post-test as a whole

This comparison consisted of total scores of both the groups out of 2,600 marks each.

Table 2: Raw scores in Pre-test and Post-test

\begin{tabular}{|l|r|r|r|r|}
\hline \multirow{2}{*}{ Group } & \multicolumn{2}{|c|}{ Total Score in } & \multirow{2}{*}{ D } & \multirow{2}{*}{ D\% } \\
\cline { 2 - 3 } & Pre-test & Post-test & & \\
\hline Exp. & 893 & 1,054 & 161 & 15.27 \\
\hline Con. & 887 & 996 & 109 & 10.94 \\
\hline $\begin{array}{l}\text { Group wise } \\
\text { Difference }\end{array}$ & 6 & 58 & 52 & 4.33 \\
\hline
\end{tabular}

The total raw score of experimental group in pre-test was 893 and it was 1,054 in the post-test, the score increased by 161 . The increased percentage was 15.27.

Likewise, the total raw score of controlled group in the pre-test was 887 and it was 996 in the post-test. The score increased by 109 . The increased percentage was 10.94 .

It showed that the raw score of experimental group in pre-test was more by 6 then that of controlled group and it was more by 58 in the post-test. The difference percentage was 4.33 . So the performance of experimental group in the post test was more by $4.33 \%$ than that of controlled group.
Average scores of both the groups in pre-test and post-test

This comparison consisted of average score, difference of the average score experimental, controlled group in the pre-test, and the posttest.

Table 3: Average Scores in Pre-test and Post-test

\begin{tabular}{|c|r|r|r|r|}
\hline \multirow{2}{*}{ Test } & \multicolumn{2}{|c|}{ Average Score } & \multirow{2}{*}{ D } & \multirow{2}{*}{ D\% } \\
\cline { 2 - 3 } & Exp. Group & Con. Group & & \\
\hline Pre-test & 34.34 & 34.11 & 0.23 & 0.66 \\
\hline Post-test & 40.53 & 38.30 & 2.23 & 5.50 \\
\hline
\end{tabular}

The above table shows, in the pre-test the experimental group had 34.34 average score and controlled group had 34.11, where difference is 0.23 . Similarly, in the post-test, the experimental group had 40.53 average score and controlled group had 38.30, where difference is 2.23 . It showed that the experimental group had only $0.66 \%$ more average score than that of controlled group in the pre-test but in the post-test it has $5.50 \%$ more average score than that of controlled group.

\section{Item-based comparison}

This comparison consists five questions; describing plan, person, place, narrating event and narrating story:

Table 4: Result in Describing Plans/Activities

\begin{tabular}{|c|c|c|c|c|}
\hline 气̃ & 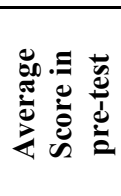 & 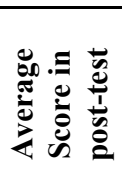 & 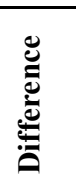 & 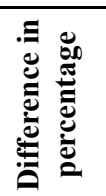 \\
\hline & & & & 13.72 \\
\hline ontrolled & 7.57 & 8.42 & 0.85 & 10. \\
\hline
\end{tabular}

The average score of experimental group in pre-test was 8.42 and it was 9.76 in the post-test. The score increased by 1.34 in average. The increased percentage was 13.72 . 
Likewise, the average score of controlled group in pre-test was 7.57 and it was 8.42 in the post-test. The score increased by 0.85 in average. The increased percentage was 10.09 .

Therefore, the performance of experimental group in this item was slightly better than that of controlled group (by 3.63 percent).

Table 5: Result in Describing Person

\begin{tabular}{|l|r|r|r|r|}
\hline Group & $\begin{array}{c}\text { AV. Score } \\
\text { in pre-test }\end{array}$ & $\begin{array}{c}\text { AV. Score } \\
\text { in post-test }\end{array}$ & \multicolumn{1}{|c|}{ D } & D\% \\
\hline Exp. & 8 & 9.11 & 1.11 & 12.18 \\
\hline Con. & 7.34 & 7.84 & 0.5 & 6.37 \\
\hline
\end{tabular}

The average score of experimental group in pre-test was 8 and it was 9.11 in the post-test, the score increased by 1.11 in average. The increased percentage was 12.18 .

Likewise, the average score of controlled group in the pre-test was 7.34 and it was 7.84 in the post-test. The score increased by 0.5 in average. The increased percentage was 6.37 .

Therefore, the performance of experimental group in this item was more than that of controlled group by 5.81 percent.

Table 6: Result in Describing Place

\begin{tabular}{|l|r|r|c|c|}
\hline Group & $\begin{array}{c}\text { AV. Score } \\
\text { in pre-test }\end{array}$ & $\begin{array}{c}\text { AV. Score } \\
\text { in post-test }\end{array}$ & D & D\% \\
\hline Exp. & 7.46 & 8.53 & 1.07 & 12.54 \\
\hline Con. & 7.5 & 8.42 & 0.92 & 10.92 \\
\hline
\end{tabular}

The average score of experimental group in pre-test was 7.46 and it was 8.53 in the post-test, the score increased by 1.07 in average. The increased percentage was 12.54 .

Likewise, the average score of controlled group in the pre-test was 7.5 and it was 8.42 in the post-test. The score increased by 0.83 in average, the average increased percentage was 10.92.

Therefore, the experimental group was slightly better than that of controlled group in this item as the difference was only 1.62 percent.

Table 7: Result in Narrating Event

\begin{tabular}{|l|r|r|c|c|}
\hline Group & $\begin{array}{c}\text { AV. Score } \\
\text { in pre-test }\end{array}$ & $\begin{array}{c}\text { AV. Score } \\
\text { in post-test }\end{array}$ & D & D\% \\
\hline Exp. & 5.57 & 6.25 & 0.68 & 10.88 \\
\hline Con. & 6.05 & 6.26 & 0.21 & 3.35 \\
\hline
\end{tabular}

The average score of experimental group in pretest was 5.57 and it was 6.25 in the post-test, the score increased by 0.68 in average. The increased percentage was 10.88 .

Likewise, the average score of controlled group in the pre-test was 6.05 and it was 6.25 in the post-test, the score increased by 0.21 in average. The increased percentage was 3.35.

Therefore, the performance of experimental group in this item was better than that of controlled group by 7.53 percentage.

Table 8: Result in Writing / Narrating Story

\begin{tabular}{|l|r|r|c|c|}
\hline Group & $\begin{array}{c}\text { AV. Score } \\
\text { in pre-test }\end{array}$ & $\begin{array}{c}\text { AV. Score } \\
\text { in post-test }\end{array}$ & D & D\% \\
\hline Exp. & 6.51 & 7.64 & 1.13 & 14.79 \\
\hline Con & 7.07 & 7.9 & 0.83 & 10.50 \\
\hline
\end{tabular}

The average score of experimental group in pretest was 6.51 and it was 7.64 in the post-test, the score increased by 1.13 in average. The increased percentage was 14.79 .

Likewise, the average score of controlled group in the pre-test was 7.07 and it was 7.9 in the post-test, the score increased by 0.83 in average. The increased percentage was 10.50 .

It showed that the performance of experimental group in this item was more than that of controlled group by 4.29 percent.

Average increment of the item-based comparison

The average increment of experimental group and controlled group in each item is presented as follows. 
Table 9: Average Increment of the Item-based Comparison

\begin{tabular}{|l|r|r|r|}
\hline \multicolumn{1}{|c|}{ Item } & \multicolumn{1}{|c|}{$\begin{array}{c}\text { Exp. } \\
\text { group } \\
\text { in \% }\end{array}$} & $\begin{array}{c}\text { Con. } \\
\text { group } \\
\text { in \% }\end{array}$ & $\begin{array}{c}\text { Difference } \\
\text { between Exp. } \\
\text { and Con. } \\
\text { groups }\end{array}$ \\
\hline $\begin{array}{l}\text { Describing } \\
\text { Plans/Activities }\end{array}$ & 13.72 & 10.09 & 3.63 \\
\hline Describing Person & 12.18 & 6.37 & 5.81 \\
\hline Describing Place & 12.54 & 10.92 & 1.62 \\
\hline Narrating Event & 10.88 & 3.35 & 7.53 \\
\hline Narrating Story & 14.79 & 10.50 & 4.29 \\
\hline Total & 64.11 & 41.23 & 22.88 \\
\hline Average & 12.82 & 8.24 & 4.57 \\
\hline
\end{tabular}

The table shows that the experimental group had 13.72 average increment percentage in describing plans/activities and controlled group had 10.09 in the same item. In this way, the experimental group had 3.63 percentages more average increment. Likewise, the experimental group had 12.18 percent average increment in describing person and controlled group had 6.37 average increment percentage. Thus in this item experimental group had 5.81\% more average increment. In describing place, the experimental group had $12.54 \%$ average increment and controlled group $10.92 \%$ average increment. So, experimental group had $1.62 \%$ more average increment in this item. Similarly, the experimental group had $10.88 \%$ average increment in narrating event and controlled group had $3.35 \%$ average increment in the same item. Thus experimental group had $7.53 \%$ more average increment in this item. In the same way, experimental group had $14.79 \%$ average increment in narrating/writing story and controlled group had $10.50 \%$ average increment and shows that experimental group had $4.29 \%$ more average increment in this item.

In this way, experimental group had $12.82 \%$ average increment in total and controlled group had $8.24 \%$. Thus, experimental group had 4.57 more average increment in totality. The highest difference was in narrating event and the lowest in describing place.

\section{Findings and conclusion}

After the completion of data analysis, the researcher has concluded the following findings:

- The increased raw score of experimental group from pre-test to post-test is 161 , which is 15.27 percent.

- The increased raw score of controlled group from pre-test to post-test is 109 , which is 10.94 percent.

- The average increment score of the experimental group is 11.44 percent more than that of controled group.

- The average increment of experimental group is 32.05 percent whereas that of controlled group is 20.61 percent as a whole.

- Among the five items, the highest increment percentage is 7.53 in narrating event and the lowest increment percentage is 1.62 , in describing a place.

Thus, we really found the effectiveness of guided writing in teaching composition from the outcome of average increment shows that experimental group performed better than that of controlled group as a whole.

\section{About the author}

Mr. Khatri is a Teaching Assistant at Surkhet Campus Education. He is also Training Co-ordinator of NELTA Branch Surkhet. He has presented a couple of papers in seminars and workshops as well published some articles in different journals. His interest lies on teacher training, second language acquisition and research. 


\section{References}

Khaniya, T.R. (2005). Examination for enhanced learning: Kathmandu: Millennium Publications.

Pincas, A. (1993). Teaching English writing. London: McMillan Publisher Ltd.
Raines, A. (1983). Techniques in teaching writing. Oxford: Oxford University Press.

Rivers, M.W. (1968). Teaching foreign language skills. Chicago: The University of Chicago Press.

\section{Appendix}

\section{Test}

Time: $2 \mathrm{hrs}$

F.M.: 100

The test item is prepared to collect the data for the purpose of a research study on 'The Effectiveness of Guided Writing in Teaching Composition'. I promise that your creations will be confidential. Therefore I'd like to request to the respected students to participate by your heart. Please, supply required information in the following:

Name:

Class:

Sex: Male/Female Roll No.:

\section{Answer the Following Questions}

Q.N.1. Write a paragraph describing in about 150 words how you will spend your holidays. (describing activities/plans)

Q.N.2. Describe a person in about 150 words on the topic 'My Best Friend' (describing person) (20)

Q.N.3. Describe your village/town in about 150 words. (describing place)

Q.N.4. Write a short description in about 150 words about an educational tour that you have ever made. (narrating event)

Q.N.5. Write a story in about 150 words that you have ever heard or read. (writing/narrating story)

[Thank you for your kind co-operation] 